\title{
Ruptured abdominal aortic aneurysm: prognostic factors
}

\author{
Aneurisma de aorta abdominal roto: fatores prognósticos \\ D enise Rabelo da Silveira, Vanessa Prado dos Santos, Aline Faria Lamaita, \\ H enrique Jorge $G$ uedes N eto, Alvaro Razuk Filho, Valter Castelli Jr., Roberto Augusto C affaro*
}

\begin{abstract}
O bjective: To analyze the prognostic factors related to the mortality of ruptured abdominal aortic aneurysm.

M ethod: Seventy-two patients who suffered ruptured abdominal aortic aneurysm and were operated in the period between 1976 and 2000 by the Vascular Surgery U nit of the Santa C asa de São Paulo School of M edical Sciences were retrospectively analyzed.

Results: The descriptive analysis of the data shows a mean age of 67.93 years, with a standard deviation of $11.58,32 \%$ female and $68 \%$ male. Of the total number, $28 \%$ had a previous history of aneurysm and $72 \%$ werenot aware of the disease. M ean systolic blood pressure during hospital admission was $96.53 \mathrm{mmH}$ g. Pain was present in $100 \%$ of the patients, as well as throbbing abdominal mass. In $93 \%$ of the cases the location of the aneurysm rupture was the retroperitoneum, $4 \%$ in the duodenum, and $2 \%$ in the free peritoneum.

Conclusion: The prognostic factors related to mortality and morbidity that demonstrated statistical significance were: age, initial blood pressure at hospital admission, diuresis during surgery, volume infused, and creatinine levels.

Key words: ruptured aneurysm, abdominal aortic aneurysm, morbidity.
\end{abstract}

The rate of aortic aneurysms is estimated to be $2.5 \%$ in the male population between 65 and 74 years, possibly reaching up to $9 \%$ in patients over 75 years of age. ${ }^{1}$ In the period between 1951 and 1980, a significant increase was observed in the rate of abdominal aortic aneurysm (AAA) from 12.2/ 100,000 to $36.2 / 100,000$ inhabitants. $^{2,3}$

\footnotetext{
* Department of Surgery, School of Medical Sciences, Santa Casa de São Paulo, São Paulo, SP

Article submitted on May 19, 2005, accepted on October 13, 2005.
}

\section{Resumo}

O bjetivo: Analisar fatores prognósticos relacionados com a letalidade dos doentes com aneurisma de aorta abdominal roto.

M étodo: Foram analisados, retrospectivamente, 72 doentes portadores de aneurisma de aorta abdominal roto, operados no período de 1976 a 2000 pela disciplina de Cirurgia Vascular da Santa C asa de São Paulo.

Resultados: A análise descritiva dos dados mostra média de idade de 67,93 anos, com desvio padrão de 11,58 anos, sendo $32 \%$ do sexo feminino e $68 \%$ do sexo masculino. Do total, $28 \%$ tinham história prévia de aneurisma e $72 \%$ desconheciam a doença. A pressão arterial sistólica na admissão foi de $96,53 \mathrm{mmH}$ g. A dor esteve presente em $100 \%$ dos doentes, assim como massa abdominal pulsátil. 0 local de rompimento do aneurisma foi em $93 \%$ dos casos para o retroperitônio, $4 \%$ para o duodeno e $2 \%$ para peritônio livre.

C onclusão: 0 s fatores prognósticos relacionados à letal idade que se mostraram com significância estatística foram: idade, pressão arterial admissional, diurese intra-operatória, volume infundido e creatinina admissional.

Palavras-chaves: aneurisma roto, aneurisma da aorta abdominal, morbidade.

Ruptured AAA is the most frequent and most serious complication, with 20-40/100,000 cases each year, and could bethe first aneurysmal manifestation in up to $50 \%$ of the cases, representing $1.1 \%$ of all deaths in the male population over the age of $50,1,4$ Its rate rises relativeto age and reaches its peak in the 80-89 male age group, with rates of $112.7 / 100,000$ and rates of $67.7 / 100,000$ in women older than 90 years. $^{2}$

The mortality of ruptured AAA varies between 15 and $68 \%$, with mean of $50 \%$, which demonstrates a great contrast when compared to the mortality of $2.9 \%$ in patients submitted to optional/el ective surgery. $2,5,6$ 
M ost authorsspeculated asignificant risein themortality of these patients, approximately $90 \%$, if patients with homedeathsareincluded, dueto thefact that only $50 \%$ of these arrive to the hospital alive. ${ }^{1,5,7}$

Due to significant improvements of the survival rate of patients with this affliction in the last decade attributed to the progress in all treatment stages - from prehospital care to more developed surgical and anesthetic techniques - a more detailed study was virtually mandatory to find out why there is such elevated inferior prognostic rates in patients with ruptured AAA. ${ }^{2,8}$

$\mathrm{H}$ emorrhagic shock and reperfusion/ischemic syndrome may lead to tissue lesions with the liberation of freeradicals, activating neutrophilsand therel ease of inflammatory mediators. Freeradicalscauselipoprotein membranelesions causing changes in cellular function, contributing to post-surgery multipleorgan and system failure, which explains the higher difficulty to treat these patients and may explain the poor prognostic, despite all the advanced techniques mentioned in the literature. $^{9}$

All patients presented a diversity of factors that determined agreater predisposition to aneurysm rupture, and aworseprognosisafter surgical treatment of ruptured AAA. Therefore, there is a need for understanding the contribution for the prognosis of each of these factors individually. ${ }^{2,10} 0$ ther authorsin thelast decadestudied factorsthat could beused asearly risk factorspredisposing to increased mortality. 1,2,5,6,11

Thefactorsmost frequently studied can be divided into preoperative (previous coronary disease, chronic obstructive pulmonary disease, systolic blood pressure, hematocrit, creatinine, gender and age) and intraoperative (aortic clamping time, location of aortic clamping, surgery duration, diuresis, and infusion volume). $1,2,5,6,8,11$

The goal of this study was to analyze prognostic factorsthat determine premature death in patientswith ruptured AAA.

\section{Patients and methods}

A retrospective analysis was done of all cases of ruptured AAA admitted to the Emergency Service of the Santa C asa de M i sericórdia H ospital de São Paulo from January 1976 to December 2000 that were submitted to surgical treatment by the Vascular Surgery U nit of this service. All patients admitted with ruptured AAA in the emergency room were submitted to surgical treatment, and all of them were included for analysis, even the ones who died in the operating room.

Seventy-two patients were analyzed and initially included in the protocol, divided into subgroups according to the prognostic factors to be studied, and morbidity rates of each group submitted to statistical analysis. Some patients were excluded from a few subgroupsbecausethey did not haveall theinformation analyzed in this specific group factor.

Statistical analysis was made using the chi-square and Fisher's exact test, admitting a $P<0.005$. The chisquare test was used for the factors of age, gender, creatininelevel, systolic blood pressure, aortic clamping duration, volumetransfused and surgery duration. The rest of thefactors were analyzed using Fisher's exact test depending on the size of the group.

\section{Results}

The sample was comprised of $32 \%$ female patients and $68 \%$ male patients, with a general mortality rate reaching $54 \%$. M ean age was of 67.93 years, with a standard deviation of 11.58 years. Previous history of AAA was present in $28 \%$ of cases and $100 \%$ presented abdominal pain and throbbing abdominal mass when admitted to the hospital.

The aneurysms presented a mean diameter of $8.17 \mathrm{~cm}$, with a standard deviation of $2.57 \mathrm{~cm}$. The retroperitoneum was the most common location for rupture $(93 \%)$, followed by the duodenum (4\%) and free peritoneum $(2 \%)$.

M ean blood pressure was $96.53 \mathrm{mmH} \mathrm{g}$, with a standard deviation of $41.01 \mathrm{mmH} \mathrm{g}$. D uration of aortic clamping had amean of 109.71 minutes, with astandard deviation of 55.5 minutes; surgery duration had a mean time of 4.22 hours, with a standard deviation of 1.37 hours. This subgroup was composed of: 17 cases with blood pressure lower than $70 \mathrm{mmH}$ g; 27 cases higher than $119 \mathrm{mmH} \mathrm{g}$ and 28 cases in between.

When gender was analyzed as a prognostic factor, themean death ratewas $57 \%$ for male patientsand $52 \%$ for female patients, but it presented no statistical significance $(P=0.69)$, which demonstratesthat gender is not related to the mortality rate in our study.

Age proved to be a significant $(P=0.002)$ prognostic factor, with a higher death rate in the age groups between $61-70$ years $(90 \%)$ and $71-80$ years 
$(83 \%)$, showing that age and morbidity are directly proportional factors (Figure 1 ). 0 ur group study was composed of: five patients with 40-50 years (one death); 11 patients with 51-60 years (three deaths); 24 patients with $61-70$ years ( 10 deaths); 18 patients $71-80$ years ( 15 deaths); 14 patients $81-90$ years ( 11 deaths).

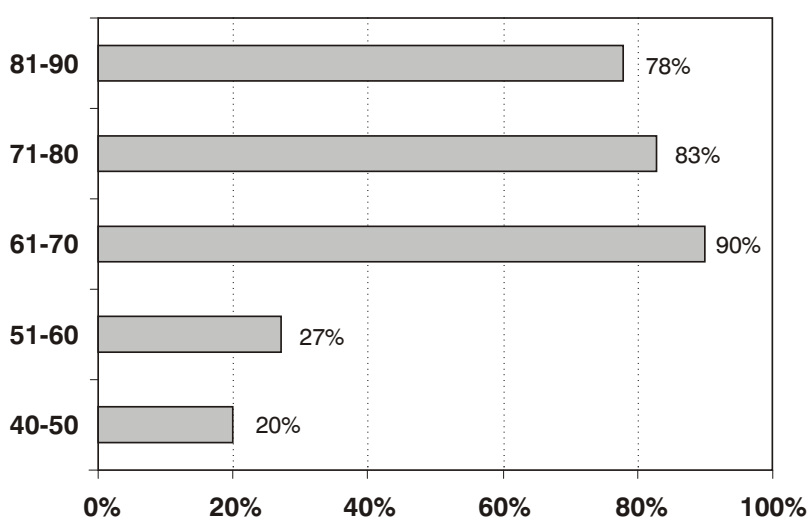

Figure 1 - Analysis of the prognostic factor of age vs. mortality

The prognostic factor of creatinine during hospital admission shows a death rate of $60 \%$ in groups with creatinine levels over $1.3 \mathrm{mg} / \mathrm{dl}(\mathrm{n}=30$ patients) and of $12.5 \%$ with creatinine lower than $1.3 \mathrm{mg} / \mathrm{dl}$ ( $\mathrm{n}=16$ patients), with a statistically significant difference between groups $(P=0.002)$ (Figure2). T wenty-six patientswereexcluded because we did not have all the information required.

Blood pressure during hospital admission proved to beinversely proportional to death rate, with a higher rate $(88 \%)$ in patients with pressure index less than $70 \mathrm{mmH} \mathrm{g}(P=0.003)$, (Figure 3).

Intraoperative diuresis was related to death rates of $100 \%$ in patients with lessthan $199 \mathrm{ml}(\mathrm{P}=0.008)$ (Figure 4). This group study was composed by: 38 patients with over $200 \mathrm{ml}$ of diuresis ( 15 deaths) and 06 patients less than $199 \mathrm{ml}$ (six deaths). Twentyeight patients were excluded because we did not have all the information required.

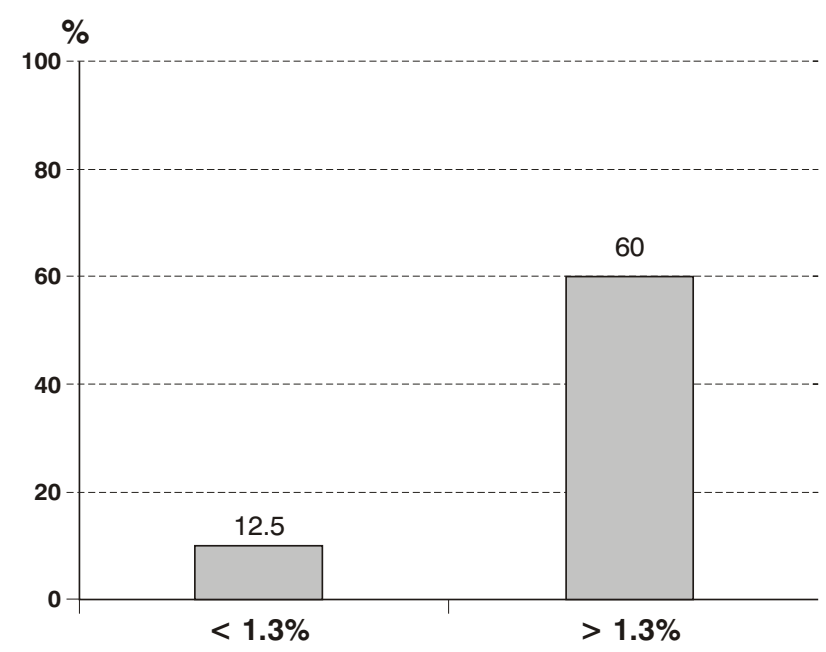

Figure 2 - Analysis of the prognostic factor of creatinine vs. mortality

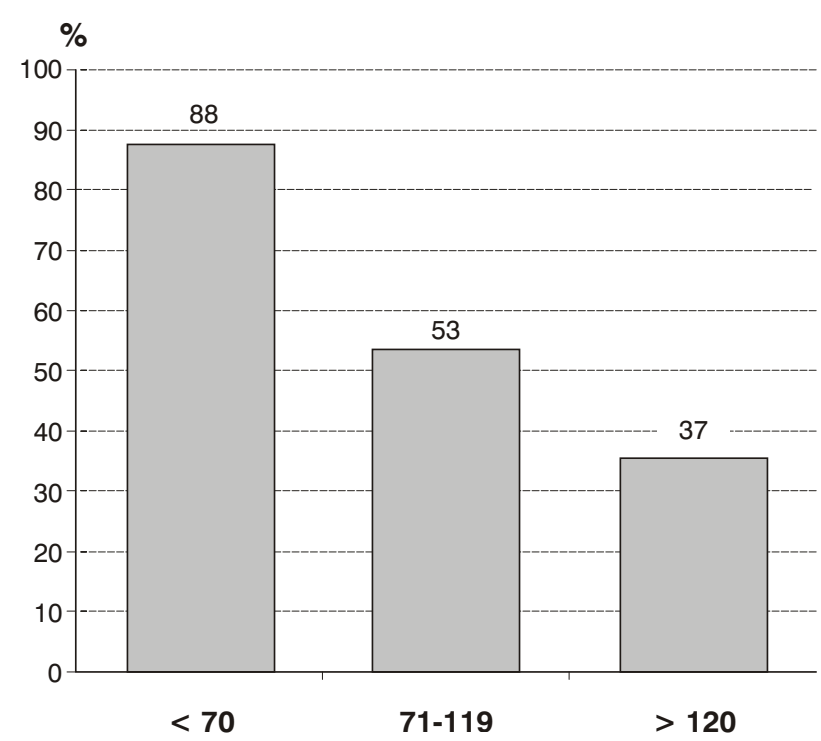

Figure 3 - Analysis of theprognostic factor of systolic blood pressure vs. mortality

Aortic clamping time did not prove to be related to prognosis ( $P=0.29$ ). M ean clamping time was 109 minutes, with a standard deviation of 55.51 minutes.

An improved prognosis was observed in patients who received between 4 and $8 \mathrm{I}$ of transfused volume (41\%) compared with patients who received over 8 I or under 4 I $(P=0.002)$, showing a statistically significant difference between volume transfused and death rate (Figure 5). 


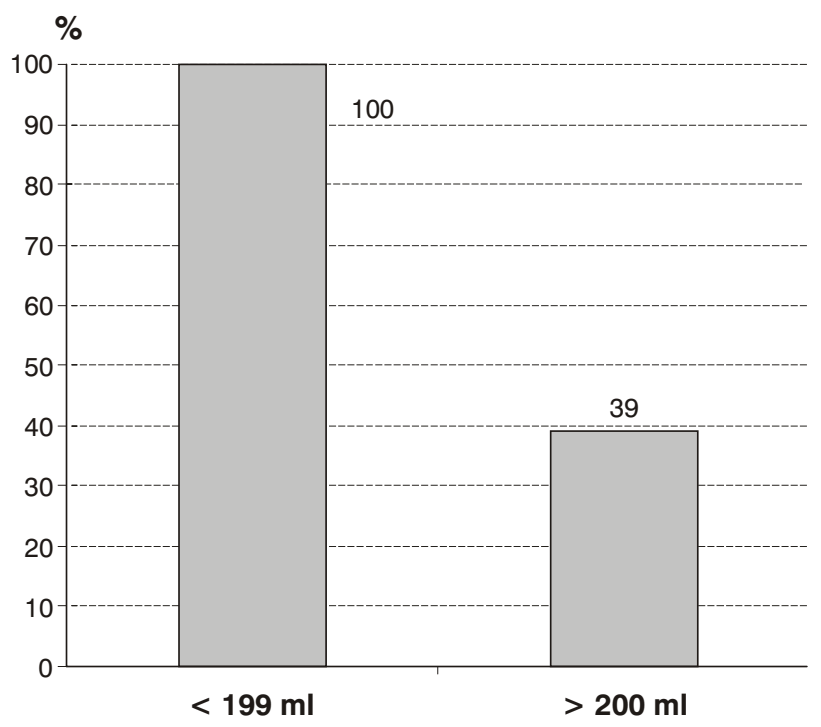

Figure 4 - Analysis of theprognostic factor of intraoperative diuresis vs. mortality

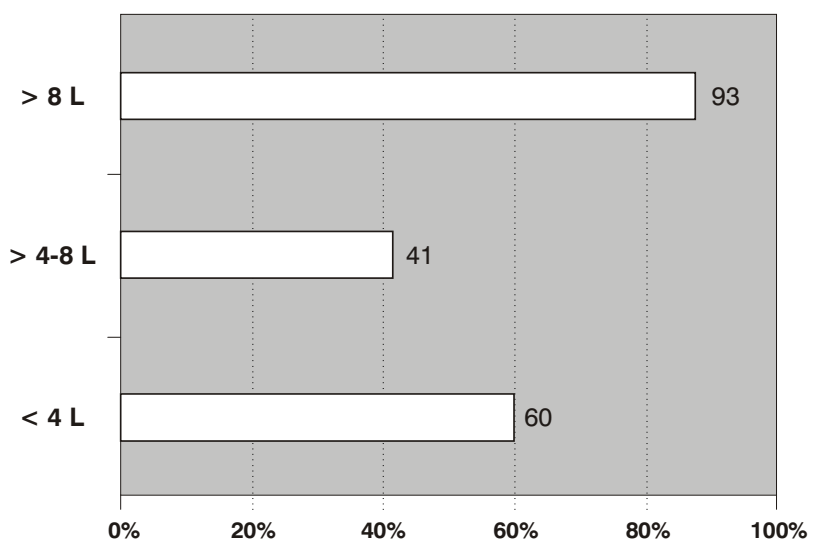

Figure 5 - Analysis of the prognostic factor of volume transfused vs. mortality

The variables of surgical time, hematocrit, and aneurysm size are not related to a better or worse prognosis. O ur group study was comprised of 23 patients with hematocrit lower than $29 \mathrm{mg} / \mathrm{dl}$ and 10 patients above it. We did not have the hematocrit value for 39 cases.

\section{Discussion}

The signs and symptoms that accompany ruptured AAA areusually dramatic. Sudden abdominal pain that radiates to the back seems to be present in nearly $70 \%$ according to the literature, and is associated to a throbbing abdominal massduring physical examination in $80 \%$ of cases. ${ }^{8}$ I n our study, thepresenceof abdominal pain and abdominal mass and mortality was 100 and $54 \%$, respectively, which isconsistent with theliterature.

Therewas a predominance of $68 \%$ in males, results that are similar to most studies that evidence gender incidence, which variesin theratio of $4: 1$ for men. ${ }^{2,5} \mathrm{As}$ in the literature, the gender factor alone does not seem to have a strong correlation with the prognosis.

Regarding the location of the ruptured aneurysm, $93 \%$ of cases were in the retroperitoneum, with only $2 \%$ occurring in the free peritoneum. In general, a higher incidence of rupture in the free peritoneum is described with a higher mortality rate, even though this is not a consensus in the literature. G loviczki et al. and W akefield et al. claim that a lower incidence of ruptures in the free peritoneum reflects an inferior prognosis for patients who would have a faster evolution and thus represents the group of home deaths, being thereforea repercussion of the pre-hospital care. 6,8

Age has been cited as an important variable for the prognosis, even though it is mainly considered a contributive factor and not an independent one. ${ }^{2,8}$ Crawford et al. and Johansson \& Swedenborg showed a higher morbidity ratein octogenarians, but agreethat theagefactor al oneshould never contrain dicatesurgical treatment. 6,12,13 Furthermore, there are authors who believe age has no association with morbidity. ${ }^{5,11}$ In our study, weobserved that theagegroup isafactor that presents a strong connection with morbidity, being directly proportional variables.

Thehypovolemic shock isthemost common factor associated to ruptured AAA. It is in general agreement that low-pressure levels during hospital admission are strong predictors of morbidity. In our unit, the place wherepreoperativepressurelevel swere determined was inversely proportional to morbidity, with higher rates with levels under $70 \mathrm{mmH} \mathrm{g}(80 \%)$. C rawford et al. ${ }^{12}$ advocate that preoperative resuscitation should be performed with little volume maintaining pressure levels between 50 and $70 \mathrm{mmH}$ g until aortic clamping is performed, due to the fact that higher pressure levels are related to the detachment of thrombus and 
subsequent hemodynamic instability. Several services believe that such low pressure levels result in a higher morbidity rate with a higher incidence of multiple organ failure. ${ }^{1,2,5,8,11}$

With regard to necessary volume restitution, we observed that patientswho received morethan $8,000 \mathrm{ml}$ and less than $4,000 \mathrm{ml}$ had a better prognosis than the patients who received intermediary levels. In general, estimated volume loss was a determinant factor in inferior prognosis in most cases and aggressive volume restitution followed such results. A better prognosiswas observed in services that advocate quick control of volumelossthrough aortic clamping or placement of an intra-aortic balloon, thuscausing a reduction in volume loss and consequent volume restitution. 8,14

Lindsay et al. ${ }^{2}$ found al ower survival ratein patients who presented creatinine levels higher than $1.3 \mathrm{mg} / \mathrm{dl}$, showing that creatinine levels are factors strongly associated with morbidity. In our study, there was a morbidity rate of $60 \%$ in patients with creatinine higher than $1.3 \mathrm{mg} / \mathrm{ml}$, with statistical analysisshowing that this factor is strongly associated with lethality. When renal function is altered before the surgical procedure, there is a higher risk of postoperative deterioration, and if this complication is present, ahigh morbidity rate is observed. ${ }^{14}$

As well as creatinine levels, intraoperative diuresis proved to be an independent indicator of morbidity with a higher lethal ity rate in patients with diuresis less than $199 \mathrm{ml}$ (100\% lethality), consistent with other studiesin theliterature, which show astrong correlation between diuresis and morbidity. ${ }^{2}$

There is an agreement that the duration of aortic clamping is a determinant factor of worse prognosis and is related to postoperative renal insufficiency, as well as sepsis and pulmonary complications; lack of such complications in our study may be explained by the size of our sample and could be better studied with an increase in thenumber of patients in a future study. 2,5,14 The Brazilian literature has some descriptions of different forms of aortic clamping that can help in surgery, such astheaortic compressor, which can be done with a smaller incision, a quicker one, stopping the bleeding while the rest of the incision is made. Another form of aortic clamping time is the use of a catheter with a balloon implanted through the brachial artery, which is insufflated in the aorta. ${ }^{15} \mathrm{U}$ nfortunately, we did not have access to those techniques and in all our cases the aortic clamping was made by clamping the infrarenal aorta in the surgery.

Similarly to clamping time, surgical duration seems to have a strong relation with an inferior prognosis, although it hasnot been evidenced in our study. Surgical duration of more than 300 minutes reveals a higher lethality, with rates of $100 \%$ in a period greater than 400 minutes. $^{8}$

Aneurysm size is classically related to aneurysm rupture. Sterpetti et al. ${ }^{16}$ report that rupture occurs in $9.5 \%$ of aneurysms smaller than $4 \mathrm{~cm}, 24.5 \%$ between 4 and $7 \mathrm{~cm}$, and $59.4 \%$ in patients with aneurysms larger than $7 \mathrm{~cm}$. H owever, thereisno scientific evidence that aneurysm size has any correlation with a better or worse prognosis after rupture.

$\mathrm{H}$ emoglobin values under $11 \mathrm{~g} / \mathrm{dl}$ are related to a morbidity of $67 \%$, while morbidity rates of $27 \%$ were observed with higher values of hemoglobin. ${ }^{8}$ Preoperative hematocrit values were assessed in our study and statistical analysisdid not match thepreviously reported findings.

A great unknown fact that motivated our study of prognostic factors related to lethality of ruptured AAA was the belief that an associated factor or associated factors could characterize inferior prognosis and, by correcting such factors could improve the evolution of these patients. In this way, several authors in the last decade investigated the relationship of isolated and associated factors.

Some authors such as Crawford et al. ${ }^{12,17}$ and G loviczki et al. ${ }^{6}$ believe that no factor or association of factors should contraindicate surgical treatment, even finding mortality rates of $90 \%$ in somesubgroups, such as female patients over the age of 80 with admission hematocrit levels lower than $25 \%$ and with mortality of $100 \%$ in patients with previous serious coronary complications.

O $n$ the other hand, Johansson \& Swedenborg ${ }^{13}$ believe that in some situations surgery should not be performed, in accordance with $\mathrm{H}$ ardman et al. ${ }^{18}$, who propose in their study that age over 76 years, loss of conscience after arrival, hemoglobin inferior to $9 \%$, ischemia identified in the electrocardiogram and creatinine levels higher than $0.19 \mathrm{mmol} / \mathrm{l}$ to be used as criteria, in which the presence of three or more of such factors should be considered as a contraindication to surgical treatment, sincethesepatientspresent mortality rate of $100 \%{ }^{13}$ 
In general it is believed that these criteria should be extremely necessary postsurgically asan additional factor to indicate or not a more aggressive clinical treatment for patients with lower chances of evolution. The endovascular treatment has been advocated as an alternative to open surgery for patients with ruptured AAA with low mortal ity rates, but with ahigh percentage of secondary interventions. ${ }^{19} \mathrm{H}$ owever, it is limited by morphologic aneurysm characteristics (including neck length and diameter) and by thepatient'shemodynamic conditions.

In summary, we demonstrated in thisstudy that the prognostic factors of age, creatinine levels, systolic blood pressure, intraoperative diuresis, and volume transfused have strong association as indicators of premature mortality in ruptured AAA.

\section{Acknowledgments}

W earegrateful to the Support Center for Scientific Publications of Santa Casa de São Paulo - School of $M$ edical Sciences for the editorial assistance.

\section{References}

1. M erlo M, Carignano G, Bitossi G, et al. Personal experience of thetreatment of ruptured aortic aneurysms. Theprognostic evaluation of some parameters. M inerva Cardioangiol. 2001;49:179-87.

2. Lindsay TF, Johnston KW. Ruptured abdominal aortic aneurysm: from diagnosisto discharge. In: Advancesin vascular surgery 3. W hittemoreAD , B andyk D , C ronenwett J , H ertzer N , W hite R, editors. C hicago: M osby Year-Book Inc.; 1995. p. 127-148.

3. Ernst CB. Abdominal aortic aneurysm. N Engl J Med. 1993;328:1167-72.

4. W ilmink TB, Q uick CR, H ubbard C S, D ay N E. Theinfluence of screening on the incidence of ruptured abdominal aortic aneurysms. J Vasc Surg. 1999;30:203-8.

5. M urphy JL, Barber GG, M cPhail N V, Scobie TK. Factors affecting survival after rupture of abdominal aortic aneurysm: effect of size on management and outcome. Can J Surg. 1990;33:201-5.

6. Gloviczki P, Pairolero PC, M ucha P Jr, et al. Ruptured abdominal aortic aneurysms: repair should not be denied. J V asc Surg. 1992;15:851-7.
7. Marston WA, Ahlquist $R$, Johnson $G J r, M$ eyer $A A$. $M$ isdiagnosis of ruptured abdominal aortic aneurysms. J V asc Surg. 1992;16:17-22.

8. W akefield TW, W hitehouseW M Jr, W u SC, et al. Abdominal aortic aneurysm rupture: statistical analysi sof factors affecting outcome of surgical treatment. Surgery. 1982;91:586-96.

9. Lindsay TF, Luo XP, Lehotay D C, et al. R uptured abdominal aortic aneurysm, a "two hit" ischemia/reperfusion injury: evidence from an analysis of oxidative products. J V asc Surg. 1999;30:219-28.

10. M eyer AA, Ahlquist RE Jr, Trunkey DD. M ortality from ruptured abdominal aortic aneurysms. A comparison of two series. Am J Surg. 1986;152:27-33.

11. H atori N, Yoshizu H, Shimizu M, et al. Prognostic factors in thesurgical treatment of ruptured abdominal aortic aneurysms. Surg Today. 2000;30:785-90.

12. Crawford ES, Saleh AS, Babb JW III, G laeser D H , Vaccaro PS, Silvers A. Infrarenal abdominal aortic aneurysm: factors influencing survival after operation performed over a 25-year period. Ann Surg. 1981;193:699-709.

13. Johansson G, Swedenborg J. Ruptured abdominal aortic aneurysms: a study of incidence and mortality. Br J Surg. 1986;73:101-3.

14. Bauer EP, R edaelli C, von-Segesser LK, T urina M I. R uptured abdominal aortic aneurysms: predictorsfor early complications and death. Surgery. 1993;114:31-5.

15. Bonamigo TP. Aneurismasrotosdaaortaabdominal. In: Brito CJ, et al. Cirurgiavascular. Vol I. Rio deJ aneiro: REVIN TER; 2002. p. 503-513.

16. Sterpetti AV, C avallaro A, C avallari N, et al. Factorsinfluencing the rupture of abdominal aortic aneurysms. Surg Gynecol O bst. 1991;173:175-8.

17. Crawford ES. Ruptured abdominal aortic aneurysm. J V asc Surg. 1991;13:348-50.

18. $\mathrm{H}$ ardman $\mathrm{DT}$, Fisher $\mathrm{CM}$, Patel M I, et al. R uptured abdominal aortic aneurysms: who should be offered surgery?] V asc Surg. 1996;23:123-9.

19. Hechelhammer $L$, Lachat $M L$, W ildermuth $S$, Bettex $D$, $M$ ayer $D$, Pfammater T. M idterm outcome of endovascular repair of ruptured abdominal aortic aneurysms. J V asc Surg. 2005;41:752-7.

\section{Correspondence:}

D enise Rabelo da Silveira

Rua São Vicente de Paula, 416/94

CEP 02350-002 - São Paulo, SP

Phone: (11) 3226.7273

Fax: (11) 3226.7273

E-mail: suely.longui@fcmscsp.edu.br 